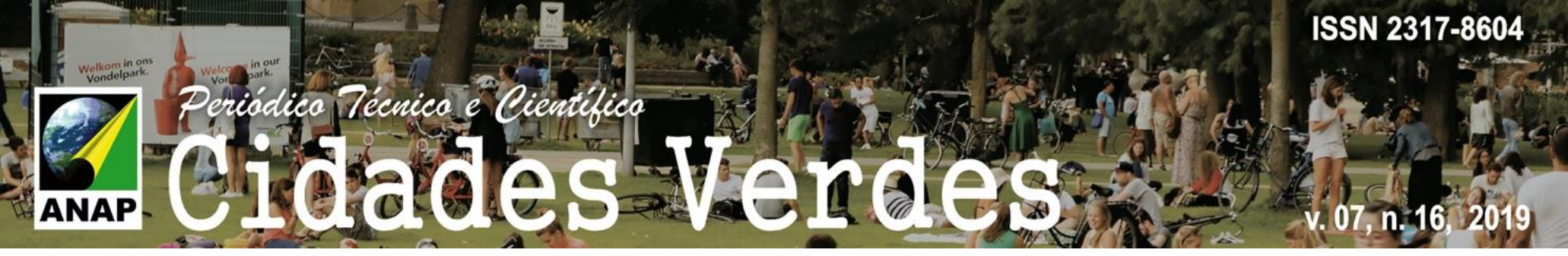

\title{
Hortas comunitárias: espaço público que contribui para o desenvolvimento sustentável da cidade de São Paulo, SP
}

Community gardens: public space that contributes to the sustainable development of the city of São Paulo, SP

Jardines comunitarios: espacio público que contribuye al desarrollo sostenible de la ciudad de São Paulo, SP

Raiza Indyra Rodrigues Rocha

Graduanda, UNINOVE, Brasil indyra.raiza@gmail.com

Ana Paula Branco do Nascimento

Doutora em Ecologia Aplicada, Brasil apbnasci@yahoo.com.br

Maria Solange Francos Mestre, Docente UNINOVE, Brasil mariasolangef@uni9.pro.br 


\section{ISSN 2317-8604}

\section{INTRODUÇÃO}

Áreas Verdes Urbanas estão associadas à qualidade de vida da população e, dentre elas, destacam-se parques, praças, jardins e, atualmente, diversas hortas comunitárias. Estas oferecem à população, além de um espaço verde, local para o desenvolvimento de projetos sociais, plantio de espécies de interesse alimentício, medicinal, além de resgatar o contato com a natureza (DORIGO e LAMANO FERREIRA, 2015).

Em 2015, foi estabelecida uma agenda mundial pela Organização das Nações Unidas contendo 17 Objetivos para o Desenvolvimento Sustentável (ODS) e 169 metas para entrarem em ação até 2030, sendo que algumas devem ser atingidas antes (ONU, 2015). Dentre estes objetivos, o ODS 2 refere-se acabar com a fome e alcançar a segurança alimentar, além de melhorar a nutrição. Desta forma, todas as estratégias para melhoria na alimentação são relevantes, uma vez que alimentação digna é um direito humano (ALMEIDA et al., 2018).

Dentre os espaços urbanos que oferecem melhor qualidade de vida aos moradores, existem espaços que podem contribuir também para melhorar a qualidade da alimentação, seja pelo consumo de plantas alimentícias e/ou medicinais, como hortas comunitárias. Estas podem estar localizadas em praças, parques (SANTOS et al. 2019) ou espaços residuais das cidades, contribuindo para complementar ou enriquecer a dieta de famílias. Desta forma, auxiliam na redução da pobreza (ODS1), sendo uma forma de agricultura urbana sustentável (ODS2; ODS 11).

Para Santos et al. (2019), as hortas envolvem processos ecológicos e sociais, promovendo benefícios individuais e comunitários, contribuindo para a sustentabilidade urbana. Dentre os benefícios sociais, a interação entre os moradores, como as trocas de conhecimento sobre o cultivo e utilização dos recursos vegetais, é muito relevante. As hortas comunitárias são cada vez mais implementadas nas cidades e consideradas nas políticas públicas (TORRES et al., 2018).

As hortas podem ser geridas por agricultores familiares, por um grupo de idosos, por uma associação de bairro e seus moradores, por donas de casa ou por crianças de uma escola local (SERAFIM e DIAS, 2013). Este espaço, além de trazer benefícios para as famílias envolvidas, pode promover a revitalização de espaços públicos e também voltar-se à geração de renda, com produção e venda de alimentos orgânicos de forma sustentável. Isso ainda pode promover benefícios nutricionais para as famílias em relação ao maior consumo de frutas e vegetais (NOVA et al., 2018).

A prática de cultivo de recursos vegetais vem crescendo nas cidades, com o resgate de valores dos moradores. No município de São Paulo há cultivo de alimentos em quintais residenciais (LAMANO-FERREIRA et al., 2015), o que contribui para a manutenção da biodiversidade local e sustentabilidade. Cabe destacar que a procura por alimentos mais saudáveis e de cultivo orgânico tem sido relatada por paulistanos consumidores de feiras orgânicas (GONÇALVES et al., 2019).

De acordo com Torres et al. (2018), as hortas urbanas são locais extremamente importantes a serem considerados no planejamento urbano, bem como sua conservação. Neste contexto, as hortas comunitárias são espaços públicos inclusivos, acessíveis e verdes, particularmente para 


\section{ISSN 2317-8604}

(1995), neste tipo de pesquisa o objeto é uma unidade social que é analisada, ou seja, um detalhamento de um ambiente por meio de uma vivência da realidade: a Horta das Flores.

As autoras participaram das atividades sociais oferecidas na horta nos meses de agosto, setembro e outubro de 2019, como mutirões, oficinas, limpeza de canteiros e plantio de hortaliças e ervas. Durante o período, foram realizados diários de campo, em que foram anotadas as informações observadas e também fotografias do espaço.

Durante o evento foram realizadas conversas informais com os tutores e com os visitantes, buscando o máximo de informações sobre a gestão e uso do espaço. Posteriormente, as informações foram compiladas e são descritas nos resultados.

\section{RESULTADOS E DISCUSSÃO}

Desde 2002 o espaço possui uma finalidade socioambiental importante para o bairro da Moóca. Em 2012, um grupo de moradores do bairro e arredores passaram a realizar a manutenção da horta existente no local, promovendo atividades comunitárias na praça aberta à população e estimulando os moradores do entorno a usufruírem do espaço. Suas atividades estão voltadas à educação ambiental, com muitas visitas de alunos do ensino fundamental. Em todo primeiro domingo do mês ocorre um mutirão voluntário, das $9 \mathrm{~h}$ às $12 \mathrm{~h}$.

No local encontram-se muitas árvores frutíferas, hortaliças, orquídeas, bromélias, composteira aberta e um viveiro, onde são cultivadas mudas de árvores nativas da Mata Atlântica e do Cerrado, que estão disponíveis para plantios voluntários. No espaço há também abelhas-jataí do projeto S.O.S Abelhas sem ferrão e, recentemente, foi estabelecida uma parceria com uma empresa sustentável para a revitalização de diversos canteiros, com plantio de aromáticas e medicinais.

Na entrada da Horta das Flores, já é possível observar a presença de palmeiras e bananeiras (Figura 2A). Seguindo à esquerda por alguns metros, há o primeiro canteiro, onde são cultivadas algumas Plantas Alimentícias Não Convencionais (PANCs), tais como: Stachys byzantina (Lamiaceae), conhecida popularmente como peixinho ou orelha-de-lebre (Figura 2B), nativa da Turquia, mas amplamente cultivada no Brasil (KINUPP; LORENZI, 2014). Virando à esquerda, em outro canteiro, pode-se observar uma espécie pertencente ao gênero Opuntia, conhecida como palma (Cactaceae), nativa do México.

Em outros canteiros (Figura 2C), espalhados por toda a horta, são cultivadas espécies como: Hibiscus sabdariffa (Malvaceae), conhecida como vinagreira ou quiabo-azedo, nativa da África e muito utilizada no nordeste brasileiro como hortaliça folhosa; Curcuma longa (Zingiberaceae), conhecida como açafrão-da-terra, nativa da Índia, cujos rizomas são utilizados para extração de um condimento de uso culinário e medicinal; Tropaeolum majus (Tropaeolaceae), popularmente chamada de capuchinha, chaguinha ou nastúrcio, nativa do México e do Peru, cujas folhas, flores e frutos são utilizados na alimentação. Todas as espécies citadas são classificadas como PANCs.

O contato direto com as PANCs é importante para que voluntários e visitantes sejam estimulados a conhecer as muitas fontes de nutrientes de origem vegetal e possa, desta forma, complementar, diversificar e enriquecer sua alimentação no dia a dia. Nos eventos abertos à 


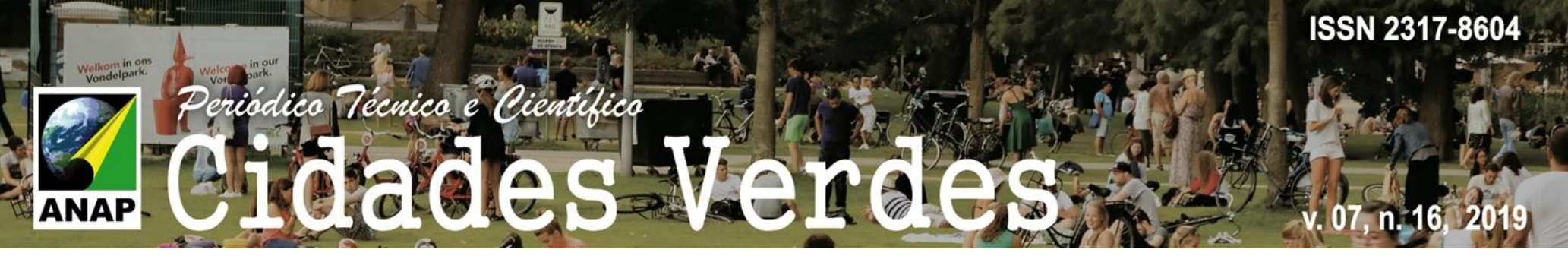

\section{CONCLUSÕES}

O espaço oferece aos moradores do entorno, aos estudantes e população em geral contato com a terra e aprendizado na prática, com mutirões e diversos eventos que lá são realizados mensalmente, todos relacionados à Educação Ambiental e Alimentação Natural. Mesmo que os moradores visitem as hortas esporadicamente, o contato que têm com a natureza, a experiência com plantio, participação em palestras ou compartilhamento de informações sobre o preparo de algum vegetal, trazem benefícios sociais e ambientais à cidade.

Sugere-se mais estudos sobre hortas urbanas, tanto em espaços públicos como praças e parques, quanto em Unidades Básicas de Saúde (UBS) e hospitais. As hortas podem contribuir ainda com oferecimento de plantas alimentícias e medicinais à população, contribuindo com a segurança alimentar e nutricional, uma vez que as plantas cultivadas podem enriquecer os pratos de uma forma segura, saudável e sustentável.

Conclui-se que as hortas comunitárias são espaços que contribuem com a sustentabilidade urbana, indo de encontro com os objetivos do desenvolvimento sustentável. O ODS 11, comunidades sustentáveis, pode ser alcançado pelo oferecimento de alimentos mais saudáveis a comunidade, o que contempla também o ODS 2 , melhoria na segurança alimentar e nutricional.

\section{REFERÊNCIAS BIBLIOGRÁFICAS}

ALMEIDA, I. C.; SÁ, I. B.; ANNA, B. M. S. O direito humano a uma alimentação digna: como a agricultura familiar e as hortas domésticas auxiliam nesse direito. Dignidade Re-Vista, v. 3, n. 6, dezembro 2018. Disponível em: http://periodicos.puc-rio.br/index.php/dignidaderevista/article/view/753/563. Acesso em: 25 out 2019.

BRASIL, Ministério do Meio Ambiente. Compostagem. Disponível em:

https://www.mma.gov.br/informma/item/7594-compostagem Acesso em 01/11/2019.

DORIGO, T.A. ; LAMANO-FERREIRA, A. P. N. Contribuições da Percepção Ambiental de Frequentadores sobre Praças e Parques no Brasil (2009-2013): Revisão Bibliográfica. Revista de Gestão Ambiental e Sustentabilidade, v. 4, p. 31 45, 2015.

GODOY, A.S. Pesquisa Qualitativa, tipos fundamentais. Revista de Administração de Empresas. São Paulo, v.35, n.3, p. 20-29, 1995.

GONÇALVES, K. S.; NASCIMENTO, A. P. B.; AQUINO, S.; RIBEIRO, A.P.; VILS, L.; FERREIRA, M. L. Percepção de Consumidores de Feiras Orgânicas da Cidade De São Paulo (SP). RAMA - Revista em Agronegócio e Meio Ambiente, v. 12, p. 1081, 2019.

KINUPP, V. F.; LORENZI, H. Plantas Alimentícias Não Convencionais (PANC) no Brasil: Guia de Identificação, Aspectos Nutricionais e Receitas Ilustradas. Nova Odessa: Instituto Plantarum de Estudos da Flora, 2014, 768 p.

LAMANO-FERREIRA, A. P. N.; FERREIRA, M. L.; FRANCOS, M. S.; MOLINA, S. M. G. Espaços residenciais urbanos e suas implicações na conservação da biodiversidade. In: Sandra Medina Benini; Jeane Aparecida Rombi de Godoy Rosin (Org.) Estudos Urbanos: uma abordagem interdisciplinar da cidade contemporânea. 1ed.Tupã: ANAP, 2015, p. 349-362.

ONU BR. Objetivo 2. Acabar com a fome, alcançar a segurança alimentar e melhoria da nutrição e promover a agricultura sustentável. Disponível em: https:// https://nacoesunidas.org/pos2015/ods2/. Acesso em: 25 out 2019. 


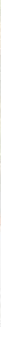

AGENDA 2030. PLATAFORMA AGENDA 2030. Os 17 Objetivos de Desenvolvimento Sustentável. Disponível em: http://www.agenda2030.com.br/. Acesso em: 25 out 2019.

MARSH, P.; GARTRELL, G.; EGG, G.; NOLAN, A.; CROSS, M. End-of-Life care in a community garden: Findings from a Participatory Action Research project in regional Australia. Health \& Place, v. 45, 2017, p. 110-116.

NGULANI, T.; SHACKLETON, C.M. Use of public urban green spaces for spiritual services in Bulawayo, Zimbabwe. Urban Forestry \& Urban Greening, v. 38, 2019, p. 97-104.

NOVA, P.; PINTO, E.; CHAVES, B.; SILVA, M. Urban organic community gardening to promote environmental sustainability practices and increase fruit, vegetables and organic food consumption. Gaceta Sanitária. 2018 Disponível em https://www.sciencedirect.com/science/article/pii/S0213911118302280?via\%3Dihub, acesso em 30.10.2019.

PETROVIC. N; SIMPSON, T.; ORLOVE, B.; DOWD-URIBEC, B. Environmental and social dimensions of community gardens in East Harlem. Landscape and Urban Planning, 183, 2019, p. 36-49.

SANTOS, L. S.; NASCIMENTO, A.P.B.; FRANCOS, M. S.; RÉGIS, M.M. Agricultura Urbana: O Caso da Horta Comunitária Orgânica do Parque Previdência, no Munícipio de São Paulo, SP. In: OLIVEIRA JUNIOR, J.M.B. (Org.) Análise Crítica das Ciências Biológicas e da Natureza. 1 ed. Ponta Grossa: Atena Editora, 2019, p. 1-17.

SERAFIM, M. P.; DIAS, R.B. Agricultura urbana: análise do Programa Horta Comunitária do Município de Maringá (PR). In: COSTA, A. B. (Org.) Tecnologia Social e Políticas Públicas. -- São Paulo: Instituto Pólis; Brasília: Fundação Banco do Brasil, 2013. p.133-152.

TORRES, A.C.; PRÉVOT, A.C.; NADOT, S. Small but powerful: The importance of French community gardens for Residentes. Landscape and Urban Planning, 2018. p.5-14. 